\title{
Breve estudo da estrutura silábica do português arcaico: a posição do glide*
}

Fernanda Elias Zucarelli Faculdades Integradas FAFIBE

\section{Abstract}

The aim of this study of Medieval Portuguese vowel sequences is the study of vowel sequences in the Cancioneiros and other Medieval Portuguese documents. The phonological status of these vowels is defined as hiatus or diphthongs. All data have been submitted to auto-segmental and metrical analyses, with particular reference to the general phonological structure of Medieval Portuguese, according to the litterature.

In the metrical approach, only the vocalic element can occupy the Nucleus position.

In falling diphthongs, all types of glides are analysed as Coda elements. Finally, it is necessary to note that MP has a significative amount of ambissyllabic sequences of vowels. 


\section{INTRODUÇÃO}

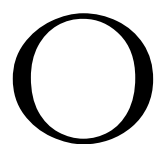

próprio título deste trabalho deixa claro o seu objetivo: tratase de um breve estudo acerca da estrutura silábica do português arcaico (de agora em diante PA), no seu período trovadoresco, enfocando, principalmente, a posição do glide. Para tal, foram focalizadas todas as silabas que ocorrem no corpus selecionado. Este foi constituído de 100 (cem) cantigas de amigo e de amor, extraídas do Cancioneiro da Biblioteca Nacional de Lisboa (de agora em diante CBN) e do Cancioneiro da Ajuda (de agora em diante CA). A análise foi baseada nas teorias fonológicas não-lineares, com o intuito de sugerir uma planilha silábica para o PA e estudar a posição do glide nessa planilha.

\section{METODOLOGIA}

Como objeto de análise, foram consideradas 100 cantigas de amigo e de amor extraídas, respectivamente, do CBN e do CA. As cantigas que constituem o corpus foram decifradas cuidadosamente com o respaldo constante de edições críticas já publicadas desses textos (NUNES, 1973; PIMPÃO, 1942; SPINA, 1991; GONÇALVES \& RAMOS, 1985). Inclusive, tomou-se o cuidado de desenvolver as abreviaturas que aparecem com freqüência nos Cancioneiros sob análise.

Posteriormente, as cantigas foram escandidas e foi feito um minucioso levantamento das estruturas silábicas e dos encontros vocálicos que aparecem no corpus. Quando se tem como objetivo a investigação de elementos de natureza não meramente segmental como no caso a descrição de estruturas silábicas - de um período de uma língua quando ainda não havia tecnologia suficiente para o arquivamento e a transmissão de dados orais, a possibilidade de escolha entre material poético e não-poético para constituição do corpus não é viável. Como os textos remanescentes do PA são todos registrados 
em um sistema de escrita de base alfabética, sem notações especiais para os fenômenos prosódicos (a não ser, na prosa, certos tipos de segmentação, na escrita, representados pela inclusão de espaços em branco entre as palavras, troca de linha, etc., que podem ajudar um pouco a clarificar essa questão), fica praticamente impossível de serem extraídas informações como as que estão sendo aqui buscadas, a respeito da estruturação silábica do português deste período, a partir de textos escritos em prosa. Como se pode ver, torna-se essencial o uso do material poético.

\section{EMBASAMENTO TEÓRICO}

Para o desenvolvimento deste trabalho, a estruturação das sílabas será comumente representada através de planilhas silábicas e pode ser apresentada em forma de árvore, como as sugeridas por Selkirk (1980) e Hogg \& McCully (1987), o modelo segue abaixo em (1):

(1)

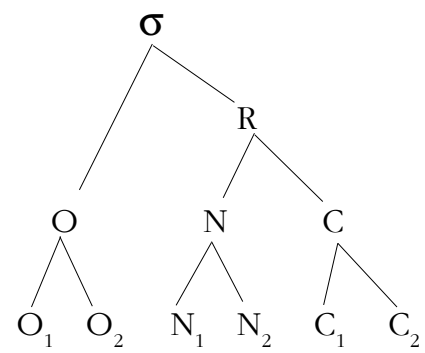

Assim, tentaremos, à luz da teoria métrica, partindo da análise das cantigas que compõem o nosso corpus, sugerir uma planilha silábica para o PA, indicando a posição do glide.

\section{INTERPRETAÇÃO FONOLÓGICA DO GLIDE E A SUGESTÃO DE UMA PLANILHA SILÁBICA PARA O PA}

A hipótese de considerar planilhas silábicas com duas posições disponíveis no núcleo para vogais e glides, na verdade, auxilia na resolução de problemas, como a falta de lugar para "ancoragem" de vogais ou consoantes, mas, no PA, não existem problemas similares 
a esse; porém, tal situação é bastante comum para outras línguas, como o inglês, por exemplo, que admite seqüências como graind, estudadas por Hogg \& McCully (1987: 41).

Segundo os dados extraídos do corpus, o PA apresenta no máximo estruturas silábicas com 4 constituintes, como se pode conferir em Bernardineli (1999: 393) e não apresenta longas seqüências de vogais e consoantes como as permitidas pela planilha acima que prevê sílabas com até 6 constituintes; nesse sentido, essa hipótese deve ser desconsiderada.

Assim, para o PA, uma segunda hipótese, a de que o glide estaria na coda, é a mais adequada, pois daria conta das estruturas silábicas da língua em questão e não deixaria posições ociosas na planilha; por isso, torna-se necessário apresentar uma planilha prevendo algumas restrições, para que não haja possibilidade de organizar estruturas silábicas agramaticais para o PA.

Lopez (1979) sugere, para o português brasileiro, um molde silábico que pode ser representado através da planilha silábica (2), como mostra Collichonn (1996: 113):

(2)

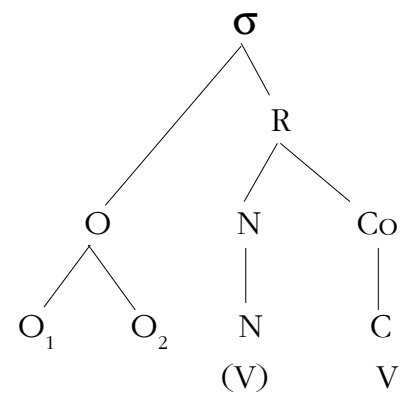

Esse molde é bastante reduzido em relação aos outros sugeridos, mas é capaz de representar quase todas as sílabas máximas (isto é, as sílabas possíveis com o maior número de segmentos) do PA, como mostram (3), (4), (5) e (6): 
(3)

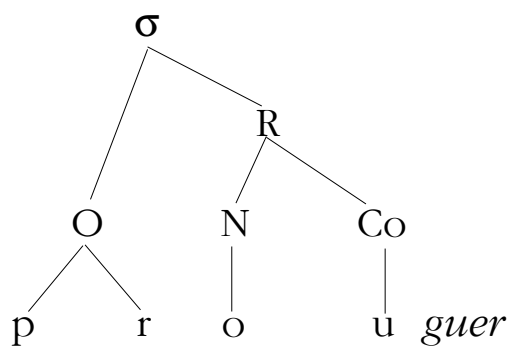

(4)

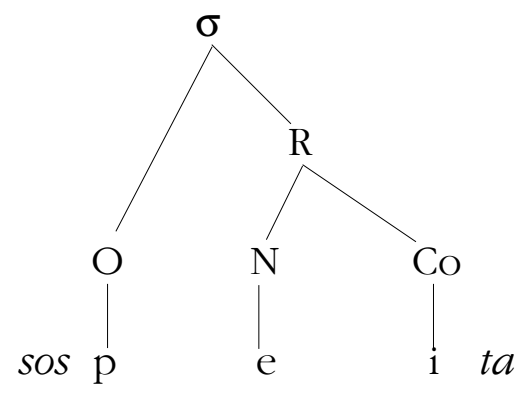

(5)

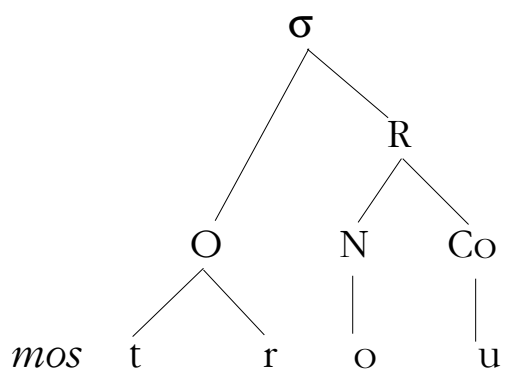

(6)

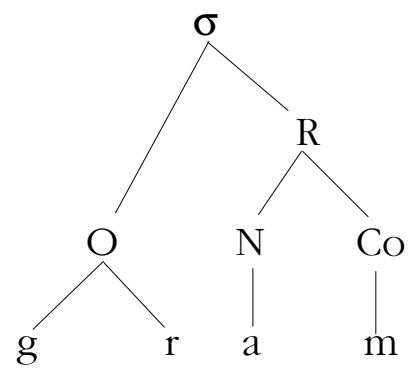


Ficam sem explicação, a partir da planilha considerada, somente ocorrências do tipo deus, mais, meus, pois, já que nesses casos temos um ditongo decrescente acrescido de um $s$, o qual ficaria sem lugar de ancoragem na estrutura silábica apresentada para o PA, com base em Lopez (1979). Surge, portanto, a necessidade de considerar as duas posições disponíveis na coda sugeridas pela estrutura apresentada em (1). Logo, podemos concluir que, para o PA, a planilha silábica ${ }^{1}$ poderia ser apresentada com os seguintes constituintes:

(7)

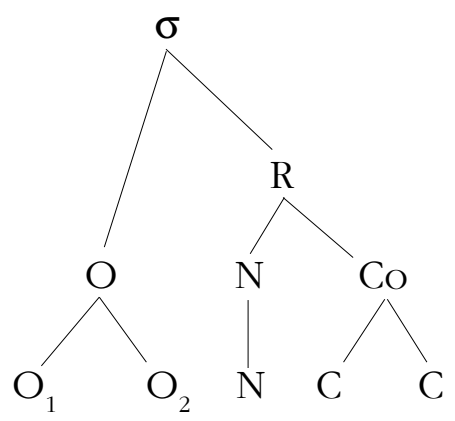

(V) G

Assim, temos uma estrutura que representa as seqüências vocálicas de maneira adequada, demonstrando que o núcleo da sílaba, sempre uma vogal, tem status diferenciado perante os outros constituintes, inclusive, perante os glides, que ficariam sempre na coda, como é possível ver em (8) e (9).

(8)

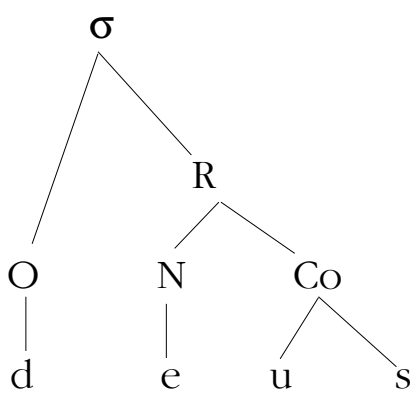


(9)

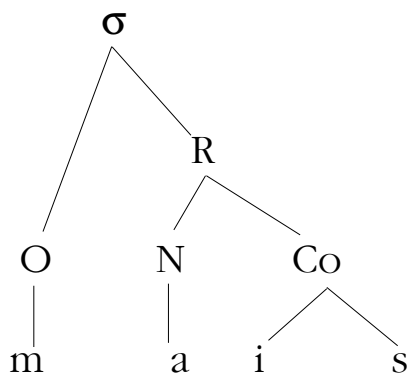

Outra hipótese é considerar o /s/ final extra-silábico, como fizeram Fikkert \& Freitas (1997), (apud SANTOS, 2001, p. 81). Neste caso, as planilhas (8') e (9') poderiam ser reescritas como:

(8')

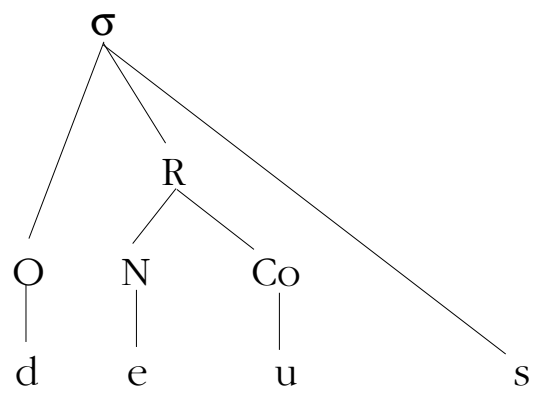

(9')

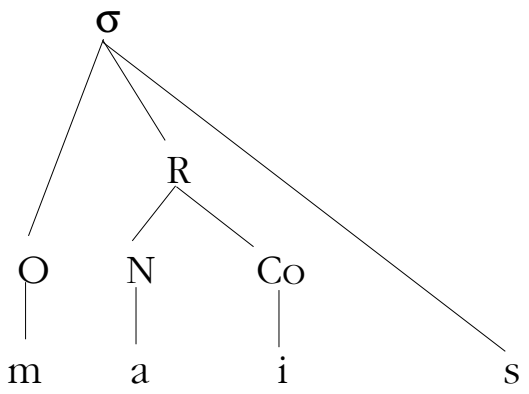

Bernardineli (1999, p. 393), após detalhado estudo das estruturas silábicas presentes em uma cantiga de D. Dinis, apresenta um quadro com os principais tipos silábicos, número de ocorrências e exemplos. Para verificar se a planilha proposta em (44) dá conta de todas as ocorrências do PA, representaremos nas planilhas abaixo alguns exemplos apresentados por Bernardineli. ${ }^{2}$ 
(10)

Tipo de sílaba: V

exemplo: $e$

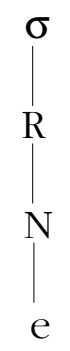

(11)

Tipo de sílaba: CV

exemplo: $n o \quad \sigma$

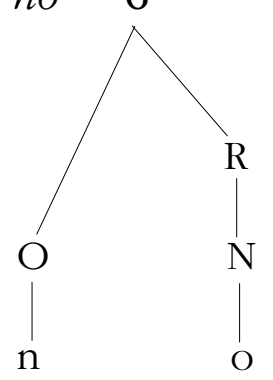

(12)

Tipo de sílaba: VC

exemplo: andar e veer

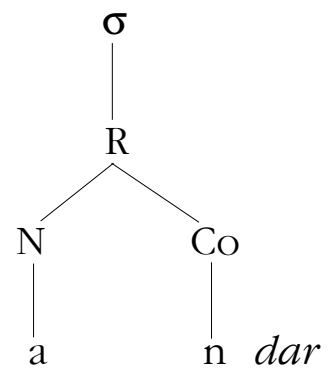


(12')

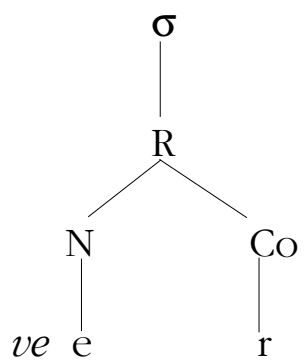

(13)

Tipo de sílaba: CVV

exemplo: meu

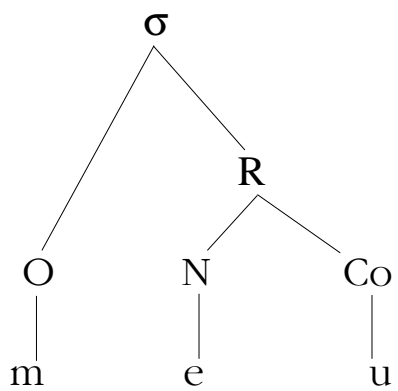

(14)

Tipo de sílaba: CVV

exemplos: coraçom, mostrou e faz

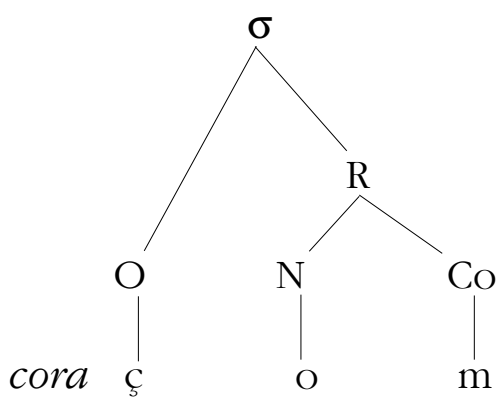


(14')

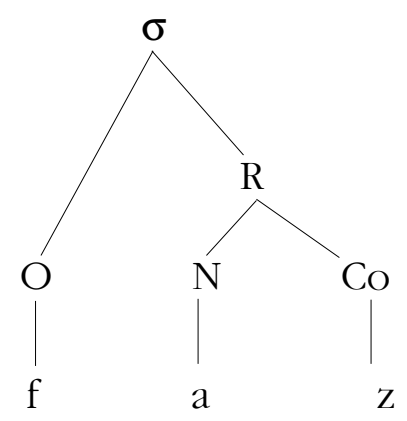

(14")

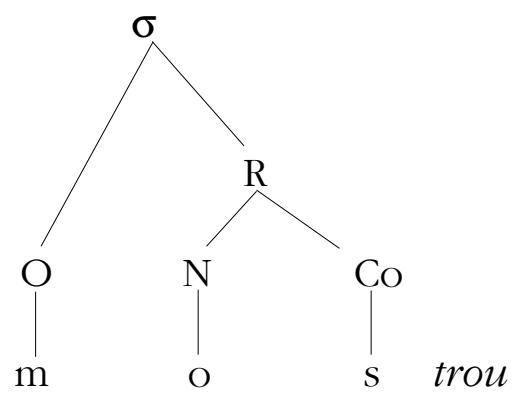

(15)

Tipo de sílaba: CVVC

exemplo: pois

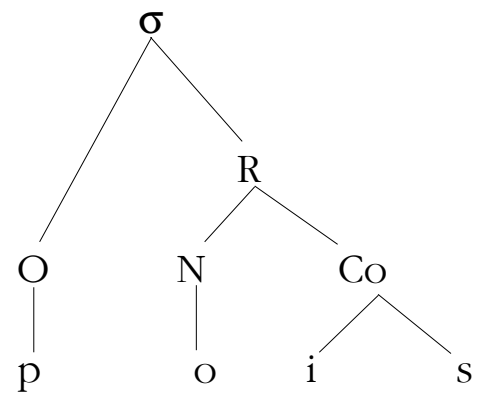


(16)

Tipo de sílaba: CCVC

exemplo: triste

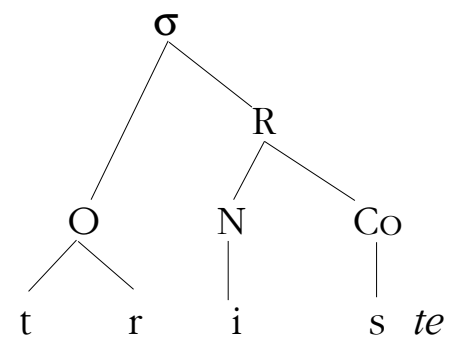

(17)

Tipo de sílaba: CCVC

exemplos: gram e traz

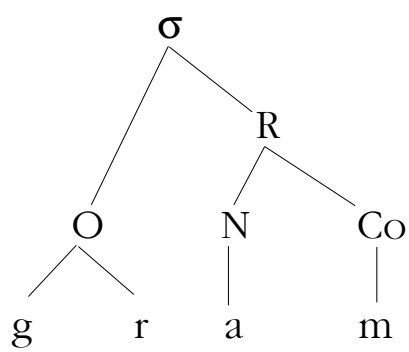

(17')

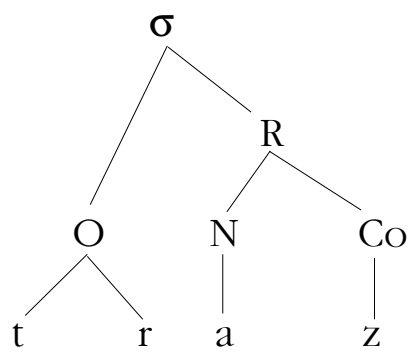

Temos, como se pode ver, os elementos /y/ e /w/ trabalhando como consoantes, travando sílabas, como em par, pai, tornando tais sílabas pesadas, proporcionando, inclusive, a atração do acento, ${ }^{3}$ no caso do PA, como explica Massini-Cagliari (1999). ${ }^{4}$ Nessa perspectiva, 
devemos interpretar o glide com o mesmo status das consoantes que proporcionam o travamento de sílabas, ou seja, posicionado na coda da estrutura silábica. Além disso, Bisol (1994), ao discutir os ditongos derivados, sugere a formação de ditongos (diacronicamente falando) a partir de consoantes geminadas, defendendo que o glide deriva da consoante que ocupava a coda, travando a sílaba.

Câmara Jr. (1969: 26-27), ao esclarecer sobre a grande predominância de sílabas livres ou abertas em português, afirma:

Sílabas travadas ou fechadas são muito menos freqüentes e com limitação muito grande das consoantes que podem figurar no aclive, isto é, como decrescentes. Em compensação, as vogais /i/ e /u/ podem figurar nesta parte da sílaba como decrescentes e assilábicas (em transcrição fonológica, respectivamente, $/ \mathrm{y} / \mathrm{e} / \mathrm{w} /$ ). Constituem a vogal silábica o chamado ditongo decrescente, como em pai e pau, que se opõem distintivamente a pá.

Ao analisar as sílabas dos ditongos como travadas, considerando $V / y, w /$ como uma modalidade de sílaba travada, assim como $V / z /, V / r)$ ou V/l, Câmara Jr. (1969) admite uma análise VC, o que implicaria considerar o glide na coda. Além disso, o estudioso prevê a sílaba sendo constituída por um aclive, um ápice e um declive. Collischonn (1996: 111) sugere o seguinte gráfico:

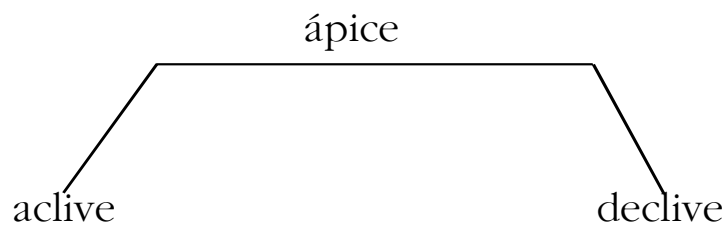

e o interpreta:

O ápice é constituído por uma vogal. O aclive é constituído por uma ou duas consoantes. O declive é constituído por uma das seguintes consoantes /S/, /r/, /l/ ou pela semivogal /y,w/. Além destas, considera a consoante nasal no declive, já que interpreta as vogais nasais como sendo fonologicamente "vogal fechada por consoante nasal". 
Tal interpretação de Collichonn (1996) nos permite acreditar que a autora defende a posição do glide na coda e sugere que Câmara Jr. (1969) também defendia essa hipótese, ${ }^{5}$ que pode, realmente, ser sustentada e sugerida como sendo a mais viável também para o PA.

Cagliari (1998, p.49) afirma que, no português brasileiro, $a$ ditongação ocorre por uma ramificação da Rima, com a vogal ocupando a posição de Núcleo e a semivogal a de Coda. Além disso, tal interpretação pode ser reforçada pela teoria desenvolvida por Spencer (1996) que sugere a intuição do falante acerca dos constituintes silábicos e apresenta a vogal como elemento central da silaba, ou seja, a vogal desempenhando papel de alicerce para a sílaba, tratando-se assim, do elemento mais proeminente. Sendo o glide uma semivogal, pode-se concluir que terá um papel secundário, com menor proeminência; para que o falante possa distinguir um ditongo de um hiato, o glide deverá ocupar uma posição na coda, como defendem os estudiosos acima citados. Como esta argumentação é válida também para o PA, conseqüentemente, teremos, na verdade, planilhas com apenas uma posição disponível no núcleo, como (18):

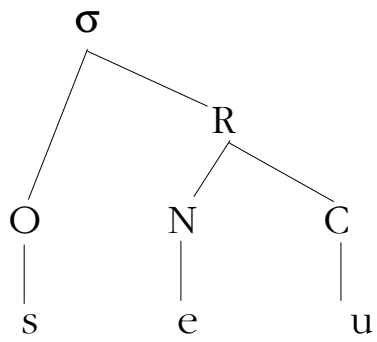

No PA, deparamo-nos com ocorrências como meu, seu, sandeu, representadas acima, que são idênticas aos ditongos atuais, mas a interpretação fonológica não é tão tranqüila quanto parece, visto que a qualidade desses encontros vocálicos pode ser discutida - o que tem importância crucial para a análise. Bisol (1989) distingue dois tipos de ditongos: os pesados (ditongos "verdadeiros", irredutíveis - ex.: reitor) e os leves (redutíveis - ex.: caixa). Se, na estrutura silábica, ambas as vogais forem moraicas, ${ }^{6}$ tratar-se-á de um ditongo pesado, 
segundo Bisol. Ao contrário, se ambas as vogais estiverem subordinadas a uma mesma mora, então, a estrutura corresponderá a um ditongo leve.

Bisol (1994, p.123) retoma a análise feita em 1989 sobre os ditongos fonológicos ("verdadeiros") e os ditongos fonéticos ("falsos") e afirma:

O primeiro, invariante (reitor, pauta) está representado na estrutura subjacente por duas vogais, como um autêntico ditongo, enquanto o segundo, que ora se manifesta ora não (peixe-pexe, feira-fera), possui na estrutura subjacente, apenas uma vogal, formando-se o glide em nível mais próximo à superfície.

Assim, temos nos verdadeiros ditongos uma rima ramificada, constituída de duas vogais, sendo que a vogal alta dessa configuração manifesta-se foneticamente como glide, como defende Bisol (1994, p.126). Tais ocorrências podem ser exemplificadas por árvores como (19):

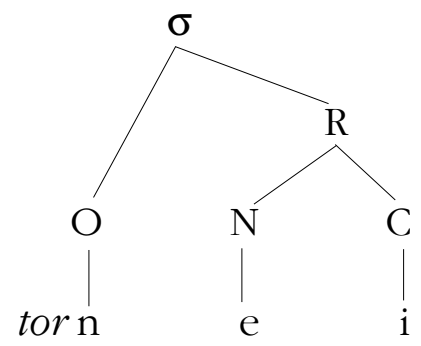

Já os "falsos ditongos", segundo Bisol (1994, p.138), não existem na forma subjacente ou de base, mas são conseqüência de um processo de assimilação, portanto, podem ou não se realizar, sendo dependentes da criação de um glide epentético.

A diferença, portanto, entre os ditongos "verdadeiros" e os "falsos" está na forma de base, ou seja, são encontros vocálicos na estrutura superficial, mas não necessariamente na estrutura profunda; em outras palavras, os primeiros apresentam duas vogais na rima desde a estrutura subjacente, os segundos, não.

Existem ainda ocorrências, como a variação moyreu e morreu, muito recorrente e que aparece, por exemplo, nos versos 5 e 6 da cantiga 35 do CA, de autoria de Paio Soares de Taveirós: 


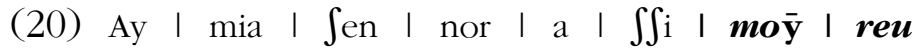

Co | mo I mo I rreu | quen | foỳ | a | mar

Neste caso, como mostra Somenzari (2001), a seqüência "RR", em morreu, é uma consoante geminada, ou seja, ocupa uma posição na coda da sílaba anterior e uma no onset da posterior; assim, podese dizer que, na ocorrência moyreu, o glide se forma da mora deixada pela consoante que trava a primeira sílaba (como se trata de uma consoante geminada, ela ocupa a coda da primeira sílaba e o onset da segunda ao mesmo tempo), trata-se, desta forma, na terminologia de Bisol (1994), de um ditongo derivado, cujo processo de formação está representado nas planilhas (21) e (22) :
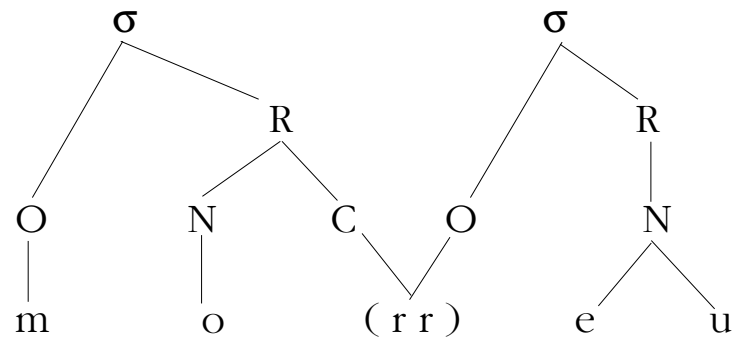

(22)
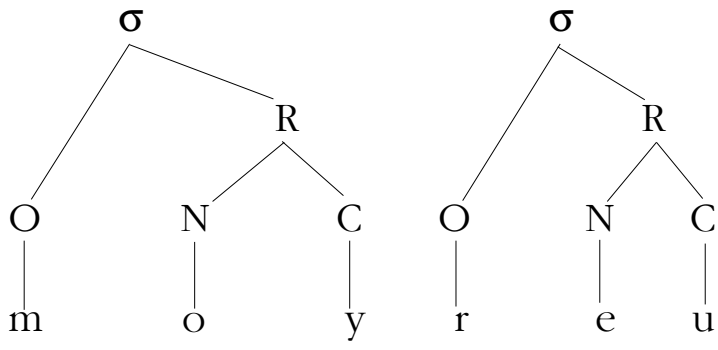

\section{CONCLUSÃO}

Assim, pode-se concluir que o glide deve ocupar posição na coda (pois as semivogais desempenham as mesmas funções das consoantes que travam sílabas, logo devem ocupar posição na coda). Além disso, foi possível sugerir uma planilha silábica para o PA - 
reduzida, se comparada às planilhas sugeridas por Selkirk (1980) e Hogg \& McCully (1987), pois sugere uma alteração: um único lugar de ancoragem no núcleo - que viabiliza a interpretação de todas as estruturas silábicas e não abre a possibilidade de serem geradas estruturas agramaticais para o PA.

\section{NOTAS}

" Esta comunicação é parte da Dissertação de Mestrado Ditongos e Hiatos nas cantigas galego-portuguesas, sendo uma das pesquisas que compõem o Projeto temático Fonologia do Português Arcaico, na Faculdade de Ciências e Letras (FCL) da UNESP, Campus de Araraquara, sob coordenação da Profa. Dra. Gladis MassiniCagliari - financiado pela FAPESP (processo №. 1997/12447-5).

${ }^{1}$ Onde $\mathrm{V}=$ vogal, $\mathrm{C}=$ consoante $\mathrm{e} \mathrm{G}=$ glide.

${ }^{2}$ Não trabalharemos todos os exemplos de Bernardineli (1999), porque algumas ocorrências precisam de maiores discussões, como $l b^{\prime} e u$, que é discutida no item 1.2.3. deste capítulo.

${ }^{3}$ Massini-Cagliari (1999, p.171) apresenta exemplos.

${ }^{4}$ Ver Massini-Cagliari (1999, p.89), que esclarece sobre possíveis divergências acerca de sílabas leves e pesadas entre diferentes línguas.

${ }^{5}$ Ver também Schane (1995).

${ }^{6}$ De acordo com o modelo métrico de Hayes (1995), para estabelecer o peso da sílaba é preciso contar o número de elementos no núcleo ou na rima, através da contagem de moras ( $\mu$ ), assim, a sílaba associada a uma mora é tida como leve e a sílaba associada a duas moras, ou mais, como pesada.

\section{REFERÊNCIAS BIBLIOGRÁFICAS}

BERNARDINELI, A. Análise da estrutura silábica em uma cantiga de D. Dinis. Estudos Lingüísticos, São Paulo: GEL, v. 28, p. 391-397, 1999.

BISOL, L. Ditongos derivados. D.E.L.T.A., v. 10, nº especial, p. 123-140, 1994.

CÂMARA JR., J. M. Problemas de Lingüistica Descritiva. 2. ed. Petrópolis: Vozes, 1969. 
CANCIONEIRO da Ajuda - Lisboa: Edições Távola Redonda. Edição Fac-similada. Cancioneiro da Ajuda. Lisboa: Sá da Costa, 1994.

CANCIONEIRO da Biblioteca Nacional (Colocci-Brancuti) Cod. 10991. Reprodução fac-similada. Lisboa: Biblioteca Nacional/Imprensa Nacional - Casa da Moeda, 1982.

COLliSCHONN, G. A sílaba em português. In: BISOL, L. Introdução a estudos de fonologia do português. Porto Alegre: Edipucrs, 1996.

GONÇALVES, E.; RAMOS, M. A. A lírica profana galego-portuguesa. 2. ed. Lisboa: Editorial Comunicação, 1985.

HOGG, R.; McCully, C. B. Metrical phonology: a coursebook. Cambridge: Cambridge University Press, 1987.

LOPEZ, B. S. The sound pattern of Brazilian Portuguese (Cariocan dialect). Los Angeles: University of California, Ann Harbor, University Microfilms International. Tese (Doutorado), University of California, 1979.

MASSINI-CAGLIARI, G. Do poético ao Lingüístico no ritmo dos trovadores: três momentos da bistória do acento. Araraquara: Laboratório Editorial FCL/UNESP; São Paulo: Cultura Acadêmica, 1999.

NUNES, J. J. Cantigas d'amigo dos trovadores galego-portugueses. Lisboa: Centro do Livro Brasileiro. $1^{a}$ edição: 1926/1929, 1073

SELKIRK, E. O. On prosodic structure and its relation to syntactic structure. Indiana: IULC, 1980.

SOMENZARI, T. Estudo do status fonológico das consoantes duplas em Português Arcaico. Comunicação apresentada no II EDiP - II Encontro de Estudos Diacrônicos do Português. Araraquara: FCL, UNESP, 29 a 31 de agosto de 2001. 